BULLETIN Bulletin hispanique

HISPANIQUE Université Michel de Montaigne Bordeaux

116-1 | 2014

Varia

\title{
Radana Štrbáková, La dinámica del léxico de la moda en el siglo XIX: estudio de neología léxica
}

Editura UniversităŢii din Bucureşti, Bucureşti, 2013

Ivo Buzek

\section{CpenEdition}

\section{Journals}

Edición electrónica

URL: http://journals.openedition.org/bulletinhispanique/3324

DOI: 10.4000/bulletinhispanique.3324

ISSN: 1775-3821

\section{Editor}

Presses universitaires de Bordeaux

\section{Edición impresa}

Fecha de publicación: 1 junio 2014

Paginación: 451-456

ISBN: 978-2-86781-931-5

ISSN: 0007-4640

\section{Referencia electrónica}

Ivo Buzek, «Radana Strbáková, La dinámica del léxico de la moda en el siglo XIX: estudio de neología léxica », Bulletin hispanique [En línea], 116-1 | 2014, Publicado el 01 junio 2014, consultado el 22 septiembre 2020. URL : http://journals.openedition.org/bulletinhispanique/3324 ; DOI : https://doi.org/ 10.4000/bulletinhispanique.3324

Este documento fue generado automáticamente el 22 septiembre 2020

Tous droits réservés 


\section{Radana Štrbáková, La dinámica del léxico de la moda en el siglo XIX: estudio de neología léxica}

Editura UniversităŢii din București, București, 2013

Ivo Buzek

\section{REFERENCIA}

Radana Štrbáková, La dinámica del léxico de la moda en el siglo XIX: estudio de neología léxica. București, Editura UniversităŢii din Bucureşti, 2013, 374 pp. - ISBN 978-606-16-0274-2.

1 La bibliografía y el estado de la cuestión referente al ámbito de la historia de la lengua española, tanto en España como en otras áreas, a veces ofrecen un panorama algo desequilibrado. Si nos limitamos tan solo a la historia del español europeo, hay áreas frecuentemente estudiadas una y otra vez, como el castellano medieval y el español áureo testimoniado a través de las obras que pertenecen al canon de la literatura española, documentos administrativos salidos del scriptorium alfonsí, documentación archivística muy variada, almacenada en archivos de diversas instituciones y que está lejos de ser estudiada sistemática y coherentemente, aunque es cierto que desde diversos ámbitos de la lingüística diacrónica se está trabajando en ello intensamente, sobre todo en las últimas dos décadas, con ayuda de la lingüística de corpus ${ }^{1}$.

2 Sin embargo, ha habido una época en la historia del español que ha pasado durante muchos años casi desapercibida a los historiadores de la lengua y que ha empezado a atraer la atención de los investigadores tan solo recientemente: el español del siglo XIX. Según los criterios de periodización que se adopten, de acuerdo con taxonomías propuestas por diversos autores, el español del siglo XIX pertenece al español moderno o contemporáneo ${ }^{2}$, pero si leemos los textos del diecinueve atentamente, nos damos cuenta de que no es un español de nuestros días, sino más bien un «caldo de cultivo» 
sobre el que se ha erigido el español que nos ha tocado presenciar y que lleva ya todas las pautas y señas de evolución que notamos en la lengua hoy en día.

3 Es, por tanto, bastante curioso que la lengua del diecinueve, tanto en España como en otras latitudes hispanófonas, haya conocido hasta las fechas que corren solo unos pocos estudios sistemáticos. Como ya hemos dicho, generalmente el español del diecinueve se suele tratar en el mismo marco temporal que el español contemporáneo o moderno ${ }^{3}$, pero últimamente el panorama empieza a cambiar ${ }^{4}$, según lo testimonia el libro de Radana Štrbáková sobre el que proponemos ofrecer un par de comentarios en los párrafos que siguen.

El trabajo de Štrbáková no pretende, por supuesto, describir la evolución del español del diecinueve en todos sus aspectos, sino que se centra en la evolución del léxico del español en España dentro de un ámbito temático concreto, el de la moda. Como expone la autora en la «Presentación» a la obra, esta «se sitúa en aquella línea de investigación que privilegia la reconstrucción de la historia del léxico desde los procesos de cambio, concretamente la neología léxica, atendiendo también los factores sociales» (p. 7). Los procesos de cambio que se estudian aquí están basados estrictamente en fuentes primarias y en su lectura se presta atención también a la dimensión social; en palabras de Štrbáková, «además de la historia de las palabras, vamos a abordar la historia de las personas que las introdujeron y difundieron, defendieron o rechazaron, a través de los textos» (pp. 7-8).

5 Uno de los principales argumentos que trae la autora para justificar el trabajo es la dinámica del cambio de la realidad social del siglo XIX -«Siglo de las revoluciones» se le llamaba-. Si se habla de la compleja, siempre cambiante y a veces dramática situación social de la España del diecinueve y su reflejo en la evolución no menos compleja y precipitada de su léxico, se suele caer a veces en tópicos de la "gran» historia: el nuevo vocabulario político-social y el léxico científico y técnico. Sin embargo, Štrbáková nos enseña en su estudio que los cambios sociales y léxicos solían demostrarse quizás con mayor vigor en las pequeñas cosas cotidianas, como son la indumentaria y la moda, y los cambios de la moda se presentan aquí como testigos de la profunda transformación social de la España decimonónica. Los cambios sociales dejaban huellas imborrables en la lengua y, sobre todo, en el léxico.

6 En primer lugar, la autora delimita con cierto detenimiento el marco temporal estudiado. Si la situación lo requiere, hace incursiones a los últimos años del siglo XVIII (no hay que olvidar que los cambios sociales a la raíz de la Revolución en Francia iban afectando a casi todas las sociedades europeas) y lo mismo se puede decir sobre la otra dirección en el vector temporal, aunque es cierto que el año 1898 fue una fecha clave en la historia de España que coincidía prácticamente con el final del siglo.

7 En cuanto al léxico-objeto de estudio propiamente dicho, este comprende, en palabras de Štrbáková, «los nombres de prendas de vestir y de sus adornos, así como las designaciones del calzado, complementos y telas. [...] Asimismo nos ocupamos de las denominaciones con que se ha designado a los tipos sociales conocidos por ir vestidos según la moda del momento» (p. 20). Para un estudio de neología como este creemos que es sumamente importante incluir la proyección social del fenómeno estudiado, es decir, la indumentaria como símbolo de estatus.

8 También nos parecen sólidamente defendidos los límites del léxico estudiado del que han quedado excluidas «las designaciones que solo tangencialmente se vinculan con el léxico de la indumentaria, como la nomenclatura de los colores, los nombres de joyas y 
bisutería, los de peinados y de arreglos florales usados como adorno del vestido y del tocado» (p. 21), igual que la terminología de profesiones y oficios relacionados con la producción de telas y vestidos, y los nombres de los establecimientos comerciales especializados en artículos de la vestimenta. El primer grupo ya queda fuera del ámbito de la indumentaria estrictamente hablando (también es cierto que los límites hay que ponerlos en algún sitio para que el trabajo no pierda cohesión) y el otro ya pertenece más bien al ámbito de estudio de terminología y cae fuera del concepto (necesariamente borroso y difuso) del léxico general o cotidiano.

Los principios metodológicos también se rigen por unos criterios claros y coherentes. En primer lugar, la autora aboga por una vinculación entre cambios históricos y cambios léxicos, interpretando pues la historia del léxico como proyección de una evolución socio-histórica de una sociedad dada durante una época concreta.

En segundo lugar, todas las unidades léxicas estudiadas aquí cuentan con un sólido respaldo documental procedente de diversas fuentes (sobre las características de los corpus hablaremos más adelante).

11 El tercer criterio es la variación léxica, es decir, se considera que los hablantes a veces utilizan palabras con significado afín como sustitutos léxicos, en virtud de necesidades estilísticas, registros o factores geográficos y sociales muy diversos. Štrbáková defiende con la adopción de este criterio -y creemos que con razón- la importancia de la variación no-denotativa para la historia del léxico.

En lo que atañe a la consideración de las unidades léxicas objeto de estudio, Štrbáková no las estudia como unidades aisladas, sino como partes del enunciado y se interesa a la vez por sus aspectos combinatorios atendiendo a diferentes combinaciones típicas que una voz puede mantener con otra. Otro aspecto importante sería la atención a las variantes formales, puesto que la reconstrucción de la historia gráfica, sobre todo en casos de extranjerismos, puede arrojar luz sobre cuestiones más amplias de la lengua del diecinueve, a saber: variaciones de vocales átonas, trueque de líquidas, y puede apuntar a distintos momentos en la evolución de las voces, cada uno de ellos vinculado a acepciones distintas o motivadas por el cambio de objeto, etc. La siguiente área de interés son las formas derivadas, ya que el número de las formas derivadas lo interpreta la autora como indicio de su nivel de arraigo en el uso.

Aparte de las consideraciones internas, no menos importantes son para la historia del léxico las observaciones de las actitudes lingüísticas de los hablantes que vivían en la época del cambio estudiada y sus opiniones (subjetivas e impresionistas, por supuesto) sobre las voces estudiadas. Sin embargo, estos comentarios personales pueden servir de buen indicio de su arraigo en el habla y de sus valores estilísticos y sociolingüísticos.

14 Y, por último, adopta Štrbáková como un criterio de neología el registro lexicográfico, aunque es cierto que es un criterio algo arbitrario y no exento de posibles polémicas. Pero es cierto que la lexicografía de autor, que proliferaba bastante en el diecinueve, puede aportar datos interesantes tanto sobre la incorporación de voces analizadas como sobre las actitudes de los hablantes de aquel entonces.

Hemos comentado más arriba que el estudio de Štrbáková es un análisis documentado y es cierto que el aporte textual es uno de los puntos fuertes del trabajo. Como es lógico, la autora ha aprovechado en principio los datos del Corpus diacrónico del español $\left(\mathrm{CORDE}^{5}\right)$. No obstante, Štrbáková es perfectamente consciente de que, por razones específicas del tema, es bastante probable que la documentación del CORDE para el 
español del siglo XIX (generalmente formada por textos literarios) pueda ofrecer una imagen distorsionada de la realidad que afectara los resultados del análisis y, por tanto, ha optado por elaborar un corpus de base propio constituido por artículos de prensa de la época estudiada (revistas de modas, periódicos con una sección de modas y otros periódicos muy variados, estos últimos procedentes de la Hemeroteca digital de la Biblioteca Nacional de España ${ }^{6}$ ), diccionarios burlescos (un género lexicográfico bastante peculiar del diecinueve que hoy aporta datos valiosísimos sobre las actitudes de los hablantes sobre la lengua de su época), sátiras y panfletos (de valor similar al del los diccionarios burlescos), las obras literarias costumbristas que no figuran en el CORDE, epistolarios y memorias, otros documentos muy variados (como manuales de etiqueta, por ejemplo) y material iconográfico (figurines y grabados de modas). De los datos que Štrbáková va aportando a lo largo de su estudio queda patente que los constituyentes del corpus base a veces han sido cruciales para la datación de las primeras documentaciones de un nutrido número de voces analizadas y han sido de gran ayuda para poder estudiar adecuadamente su evolución, lexicalización o pérdida.

Al tercer corpus lo ha llamado la autora «de referencia» y está formado por diccionarios académicos y extraacadémicos publicados en la época estudiada. Aunque el criterio lexicográfico en estudios lexicológicos como un principio que ponga fin al período neológico de una palabra nueva pueda despertar -por su aparente arbitrariedad- ciertas reticencias, es cierto que como un parámetro de relativo conocimiento de una palabra en el ámbito de una lengua dada en una época determinada es aceptable, siempre y cuando tomemos los datos aportados por diccionarios con la debida precaución (sobre todo en casos de diccionarios no académicos que, en el XIX, generalmente se limitaban a beber sin citar de las ediciones del diccionario de la Corporación, cuya nomenclatura por entonces ya estaba completamente desligada de todo respaldo textual coherente y actualizado).

17 Según nuestra opinión, la selección y la constitución de los tres pilares documentales para el estudio ha sido bastante acertada y sobre todo la metodología para confeccionar el corpus base es una aportación original que puede servir de modelo y referencia para estudios con características similares.

18 En lo que atañe a los parámetros para identificar una voz como neológica dentro de la época estudiada, Štrbáková ha adaptado acertadamente para las necesidades del proyecto una serie de características habituales en lexicología tanto sincrónica como diacrónica.

19 El primer criterio ha sido el diacrónico o temporal, es decir, la voz no debe ser documentada antes de una fecha determinada; el segundo es el lexicográfico, y según este una unidad es neológica si no aparece en los diccionarios (ya hemos mencionado más arriba que la relevancia de este criterio es relativa y que hay que tomarla con cierta precaución); otros son los criterios de inestabilidad sistémica (género, formación del plural, igual que la variación grafémica); y, finalmente, los parámetros psicológicos, es decir, si la unidad léxica es percibida por los hablantes como nueva. Apunta Štrbáková que «[1]a naturaleza de la presente investigación nos lleva a sostener que, en el caso del léxico de la indumentaria del ochocientos [estos dos últimos son] fundamentales para la determinación del proceso neológico» (p. 44).

20 Para clasificar las voces neológicas del ámbito estudiado la autora acude a la taxonomía habitual en la lexicología y las divide, en primer lugar, en creaciones externas e internas (neología externa y neología interna). 
21 Las externas las subdivide en préstamos totales y parciales (calcos y creaciones inducidas). Entre los préstamos prevalecen, como es de esperar, los galicismos (levita, pompón, negligé...), seguidos de lejos por los anglicismos (mackintosh, dandi...); la aportación de otras lenguas ha sido escasa. Como ejemplos de calcos podríamos citar los del francés entredós o gorro frigio.

Las creaciones internas obedecen también las reglas de clasificación acostumbradas y se dividen en derivados por sufijación, prefijación y parasíntesis (aunque el hecho de incluir parasíntesis bajo derivación sería discutible); por ejemplo, batín y camisolín, antilechuguino, y aballenado o encorbatinarse, respectivamente. Otro grupo numeroso de creaciones internas son los compuestos subdivididos, a su vez, en léxicos (cubre-corsé o levisac), apositivos (manga pagoda o traje Bloomer), sintagmáticos (chal de Manila o bota de agua) y otras combinaciones léxicas, representadas por varias locuciones, sobre todo adjetivas y adverbiales. Otro conjunto lo forman las creaciones sintácticas (tengañé) y el apartado se cierra con palabras creadas por otros procedimientos, en el que cabrían, por ejemplo, los deonomásticos y las creaciones expresivas lexicalizadas (por ejemplo, leopoldina y faralá, respectivamente).

23 El inventario de creaciones neológicas estudiadas comprende la parte central del trabajo y las unidades léxicas en cuestión obedecen a los criterios de neología sintetizados en los párrafos anteriores. Hay que apreciar el cuidadoso estudio que la autora le dedica a todas las voces analizadas y la abundante documentación que incluye, procedente de los corpus manejados. Estos apartados tienen forma de fichas seriadas con una estructura coherente (con pequeñas variaciones que dependen de cada caso concreto), pero en general todas las «fichas» o subcapítulos contienen información sobre su procedencia o modo de formación (e información sobre su formación y documentación en lenguas prestatarias, si son creaciones externas), la primera documentación en español y la evolución de su adaptación formal y semántica mediante citas textuales de los corpus, de acuerdo con los criterios formulados en el marco teórico del estudio.

24 Valoramos positivamente la coherencia del tratamiento. Sin embargo, si algo se echa de menos en el libro, son los índices de voces estudiadas o que figuren como subcapítulos en el índice general del libro. La disposición formal del libro invita más bien a una lectura seguida del texto, sin embargo, como la parte central del estudio se parece más a un acopio de fichas, sería conveniente facilitar también una posibilidad de consulta rápida, a manera de diccionario (histórico). Si uno solamente quiere verificar algún dato, la consulta puede tardar un buen rato y no es muy cómoda. También sería más fácil numerar y etiquetar las voces estudiadas para hacer más cómodas las referencias cruzadas. Pero esto son detalles formales que se podrían solucionar fácilmente en una próxima edición.

25 Creemos que podemos recapitular nuestras observaciones afirmando que el trabajo de Štrbáková es una aportación valiosa a la historia del español del diecinueve, puesto que contextualiza adecuadamente el campo estudiado tanto desde el punto vista interno (un estudio lexicológico) como externo (social y pragmático).

26 Aparte de los datos que ofrece, estamos convencidos de que la autora ha sabido sintetizar convincentemente también un coherente armazón teórico-metodológico sobre cómo confeccionar corpus propios originales y cómo complementar sus datos con los que ofrecen los corpus diacrónicos conocidos y disponibles para poder ofrecer al público unos resultados sólidos y fiables. La metodología ensayada aquí por Štrbáková 
podría servir de modelo para otras áreas de la historia del léxico español (no exclusivamente) del diecinueve, sobre todo en áreas del vocabulario compartido, por lo menos en parte, entre lenguajes especiales y el lenguaje común.

\section{NOTAS}

1. Cf. por ejemplo, los trabajos reunidos en Andrés Enrique-Arias (ed.), Diacronía de las lenguas iberorrománicas. Nuevas aportaciones desde la lingüística de corpus, Madrid/Frankfurt am Main: Iberoamericana/Vervuert, 2009.

2. $\mathrm{O}$ al «moderno y contemporáneo», según versa el conocido libro de Rafael Lapesa, que contiene indistintamente trabajos sobre el español de los siglos XIX y XX; el volumen se divide en varias partes temáticas, pero no según un criterio temporal (El español moderno y contemporáneo, Barcelona: Crítica, 1996).

3. Cf. Rafael Lapesa, Historia de la lengua española, $9^{\mathrm{a}}$ ed. corr. y aum., Madrid: Gredos, 1997; Pedro Álvarez de Miranda, «El léxico español, desde el siglo XVIII hasta hoy», en Rafael Cano Aguilar coord., Historia de la lengua española, $2^{\text {a }}$ ed., Barcelona: Ariel, 2005, pp. 1037-1064; o Francisco Abad Nebot, Historia general de la lengua española, Valencia: Tirant lo Blanch, 2008; entre otras posibles referencias.

4. Véanse, por ejemplo, los recientes volúmenes colectivos a cargo de Ramírez Luengo o Zamorano Aguilar (José Luis Ramírez Luengo, coord., Por sendas ignoradas. Estudios sobre el español del siglo XIX, Lugo: Axac, 2012; Alfonso Zamorano Aguilar, ed., Reflexión lingüística y lengua en la España del XIX. Marcos, panoramas y nuevas aportaciones, München: LINCOM, 2012).

5. Real Academia Española: Banco de datos (CORDE) [en línea]. Corpus diacrónico del español. http://www.rae.es.

6. Disponible en: http://hemerotecadigital.bne.es/index.vm.

\section{AUTORES}

\section{IVO BUZEK}

Filozofická fakulta Masarykovy univerzity 